\title{
C-CAT: A computer software used to analyze and select Chinese characters and character components for psychological research
}

\author{
Ming Lo ANd ChiH-Wei Hue \\ National Taiwan University, Taipei, Taiwan
}

\begin{abstract}
The Character-Component Analysis Toolkit (C-CAT) software was designed to assist researchers in constructing experimental materials using traditional Chinese characters. The software package contains two sets of character stocks: one suitable for research using literate adults as subjects and one suitable for research using schoolchildren as subjects. The software can identify linguistic properties, such as the number of strokes contained, the character-component pronunciation regularity, and the arrangement of character components within a character. Moreover, it can compute a character's linguistic frequency, neighborhood size, and phonetic validity with respect to a user-selected character stock. It can also search the selected character stock for similar characters or for character components with user-specified linguistic properties.
\end{abstract}

Most psycholinguistic theories of visual word recognition are built on alphabetic writing systems, most of which have been English (Barber \& Kutas, 2007). However, it has been shown that the visual word-recognition processes are affected by the fact that the words also represent phonology (Frost, Katz, \& Bentin, 1987). In modern Chinese, most words consist of two syllables. In written words, each syllable is represented by a character that is roughly the equivalent of a morpheme. On the surface, a character is a logogram-like symbol composed of pen strokes. Although there are indeed a small number of characters that are logograms, most frequently used characters are compounds of simpler characters, for which the mapping from orthography to phonology and semantics is complex, but not opaque. According to Karlgren's computation (see DeFrancis, 1984), about $90 \%$ of the 6,000 common traditional Chinese characters ${ }^{1}$ are semantic-phonological compounds that are composed of a semantic component (radical) and a phonetic component. The radical often provides clues as to the compound character's meaning, and the phonetic component hints at its pronunciation. Karlgren estimated that, among semantic phonological compounds, $23 \%$ show a clear relationship in meaning between radical and character, and $64 \%$ show a relationship in pronunciation between phonetic component and character. Both a radical and a phonetic component can appear in more than one character, which creates a complex relationship in semantics or in phonology among the characters sharing a common component.

There are studies designed to investigate how the principles used in character construction and alphabetic word spelling affect the two types of writings processed psychologically. Of these studies, some were designed to test the universality of the existing theories of visual word recognition, and some were designed to see whether the logographical characters afford cognitive processes different from those of alphabetical words. For instance, to test whether the activation-synthesis model of English word recognition proposed by Glushko (1979) can be used to explain Chinese character recognition, studies by Feldman and Siok (1997, 1999), Hsiao, Shillcock, and Lavidor (2006), and Taft and Zhu (1997) manipulated neighborhood size (or combinability of the stimulus characters). Neighbor characters share a component; therefore, to compute the neighborhood size of a character, a researcher must first identify the character's neighbors by examining thousands of characters, one by one. Moreover, if consistency of character pronunciation is of concern in an experiment, the neighbors of the stimulus characters have to be identified and their pronunciations have to be checked. It is not difficult to see that this laborious procedure is error prone.

\section{Character-Component Analysis Toolkit (C-CAT)}

$\mathrm{C}$-CAT is a computer software package designed to assist a researcher in constructing experimental materials using Chinese characters. The functions of C-CAT and the principles that the software uses to decompose a character into its constituent components were designed in reference to the variables manipulated in a set of 26 recently published or frequently cited studies assessing the cognitive processes involved in character recognition (Table 1). The variables manipulated in these studies could be categorized into three types: those that repre-

C.-W. Hue, hue@ntu.edu.tw 
Table 1

The Properties of Chinese Characters Manipulated in a Number of Studies Using Characters As Experimental Materials

\begin{tabular}{|c|c|}
\hline Variable & Study \\
\hline Linguistic frequency & $\begin{array}{l}\text { Ding, Peng, \& Taft, 2004; Hue, 1992, 2003; Kuo et al., 2003; Lee et al., 2004; Lee et al., 2005; Liu } \\
\text { et al., 2006; Lo, Hue, \& Tsai, 2007; Seidenberg, 1985; Taft \& Zhu, 1997; Wang, 2002, } 2006\end{array}$ \\
\hline Character complexity & $\begin{array}{l}\text { Chen, Allport, \& Marshall, 1996; Perfetti \& Tan, 1998; Seidenberg, 1985; Taft \& Zhu, 1997; Tan, } \\
\text { Feng, Fox, \& Gao, 2001; Wang, 2002, 2006; Weekes, Chen, \& Lin, } 1998\end{array}$ \\
\hline Type of characters & $\begin{array}{l}\text { Fang, Horng, \& Tzeng, 1986; Hue, 1992; Leck, Weekes, \& Chen, 1995; Wang, 2002, 2006; Weekes } \\
\text { et al., 1998; Weekes \& Zhang, } 1999\end{array}$ \\
\hline $\begin{array}{l}\text { Orthographic, semantic, and phonological } \\
\text { relationship in pairs of characters }\end{array}$ & Leck et al., 1995; Liu et al., 2006; Perfetti \& Tan, 1998; Weekes et al., 1998 \\
\hline $\begin{array}{l}\text { Position of radical or phonetic component } \\
\text { in character }\end{array}$ & $\begin{array}{l}\text { Chen et al., 1996; Ding et al., 2004; Feldman \& Siok, 1997; Hsiao, Shillcock, \& Lee, 2007; Lo et al., } \\
\text { 2007; Wang, 2002, } 2006\end{array}$ \\
\hline Character regularity & Hue, 1992; Lee et al., 2005; Seidenberg, 1985; Shu, Anderson, \& Wu, 2000; Tan et al., 2001 \\
\hline Character consistency & Fang et al., 1986; Hue, 1992; Lee et al., 2004; Lee et al., 2005; Lo et al., 2007 \\
\hline Neighborhood size & Feldman \& Siok, 1997, 1999; Hsiao, Shillcock, \& Lavidor, 2006; Taft \& Zhu, 1997 \\
\hline
\end{tabular}

sent certain qualities of a character (e.g., character type, character complexity, and linguistic frequency); those that represent the orthographic, phonological, or semantic relationships among a group of characters (e.g., character consistency); and those that represent the relationships between a character and its constituent components (e.g., character regularity). Including a second or a third type of variable in an experiment indicates that, while considering the properties of a character, a researcher takes into account not only the qualities of the character, but also the qualities of its constituent components. In the studies reviewed, all of the researchers, except Chen, Allport, and Marshall (1996) and Taft and Zhu (1997), treated a character as composed of two components, a radical plus another component, even when the "other" component is also a compound character. For example, the character "subjectively" (Figure 1A, /yi4/) is treated as a composite of the characters "moon" (Figure 1B, /yue4/) and "meaning" (Figure 1C, /yi4/), instead of "moon," "sound" (Figure 1D, /yin1/), and "heart" (Figure 1E, /xin1/). In light of the results of the analysis, C-CAT analyzes a character into at most two components, according to the following rules. First, a character is treated as composed of a radical and another component if, after the radical is stripped out, the remaining part of the character is a radical, a legal character, or a constituent component of another character. For example, the character "elder sister" (Figure 1F, /jie3/) is treated as a composite of the radical "female" (Figure $1 \mathrm{G}, / \mathrm{nv} 3 /$ ) and the remaining part (Figure $1 \mathrm{H}$ ). The remaining part is neither a radical nor a character, but C-CAT treats it as a constituent component because it is in the characters "one trillion" (Figure 1I, /zi3/) and "bed" (Figure 1J,/zi3/). Second, a character is treated as a single component unit if it is a radical, or, if after the radical is stripped out, the remaining part is neither an independent character nor a constituent component of other characters. For example, the character "several" (Figure $1 \mathrm{~K}$, /ji3/) is treated as a single-component character. The radical of the character is shown in Figure 1L. After the radical is stripped out, the remaining part is neither a character nor a component of any other character. Third, variant written forms of a radical are treated as different radicals. For ex- ample, the radicals shown in Figures $1 \mathrm{M}$ and $1 \mathrm{~N}$ are variant forms of the radical "hand" (/shou3/); C-CAT treats them as different radicals.

C-CAT is designed to provide two types of functions. It can analyze the properties of a character or of a character component, as specified by a user. For example, if a user inputs a character, C-CAT computes the number of strokes that the character comprises, its linguistic frequency, and its neighborhood size. If a user specifies a component, C-CAT computes its neighborhood size and phonetic validity (see below). It also defines a set of user-specifiable conditions (e.g., linguistic frequency, phonological relationship between a character and its phonetic component) C-CAT can use to select a small set of characters from a character stock.

C-CAT consists of an executable program and a database, which are packed in a setup file. The program performs character (and component) analysis and selection based on user input. The database contains the pronunciations of the 13,047 traditional Chinese characters included in the Microsoft East Asian languages files. In addition, using the works of Chuang and Hsieh (2005) and Hsieh, Chuang, Chang, and Hsu (1995), the assemblage of components of each of the 13,047 characters is analyzed and

\begin{tabular}{|c|c|c|c|c|}
\hline A. 臆 & M. 手 & V1. 苦 & W1. 故 & X1. 詞 \\
\hline B. 月 & N. f & V2. 哭 & W2. 苦 & X2. 飼 \\
\hline C. 意 & O. 家 & V3. 庫 & W3. 姑 & X3. 伺 \\
\hline D. 音 & P. 枯 & V4. 酷 & W4. 固 & X4. 祠 \\
\hline E. 心 & Q. 木 & V5. 褲 & W5. 胡 & X5. 嗣 \\
\hline F. 姊 & R. 古 & & W6. 枯 & \\
\hline G. 女 & S. 故 & & W7. 估 & \\
\hline H. 牙 & T. 司 & & W8. 估 & \\
\hline I. 棃 & U. 小 & & W9. 喜 & \\
\hline J. 第 & & & W10. 克 & \\
\hline K. 幾 & & & W11. 居 & \\
\hline & & & & \\
\hline
\end{tabular}

Figure 1. Sample characters used in the present article. 
A

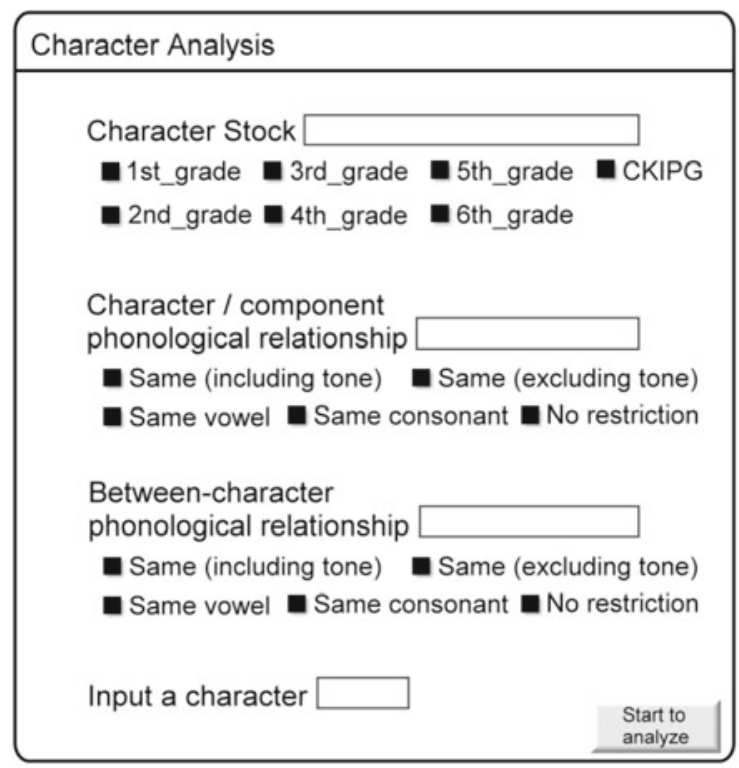

C

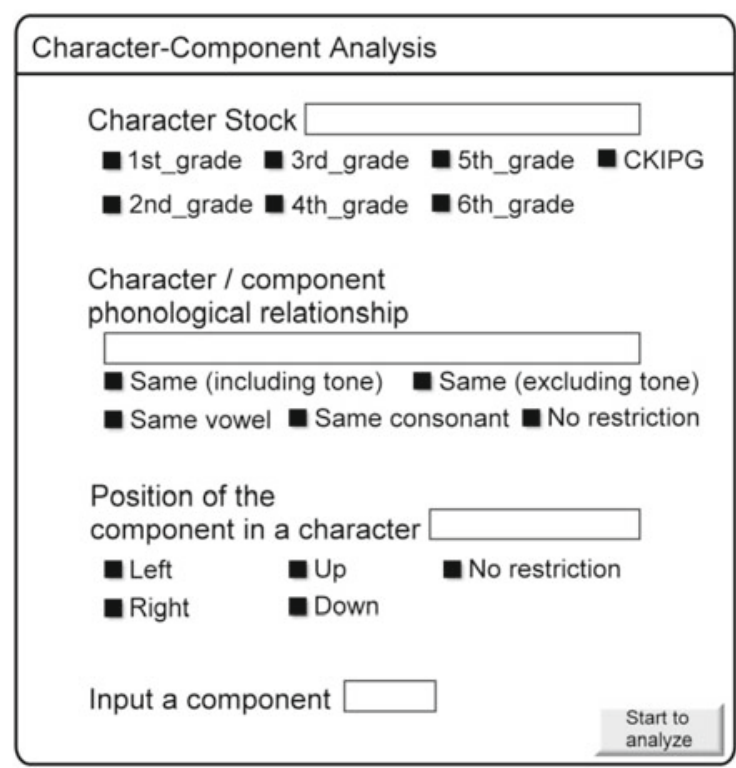

B

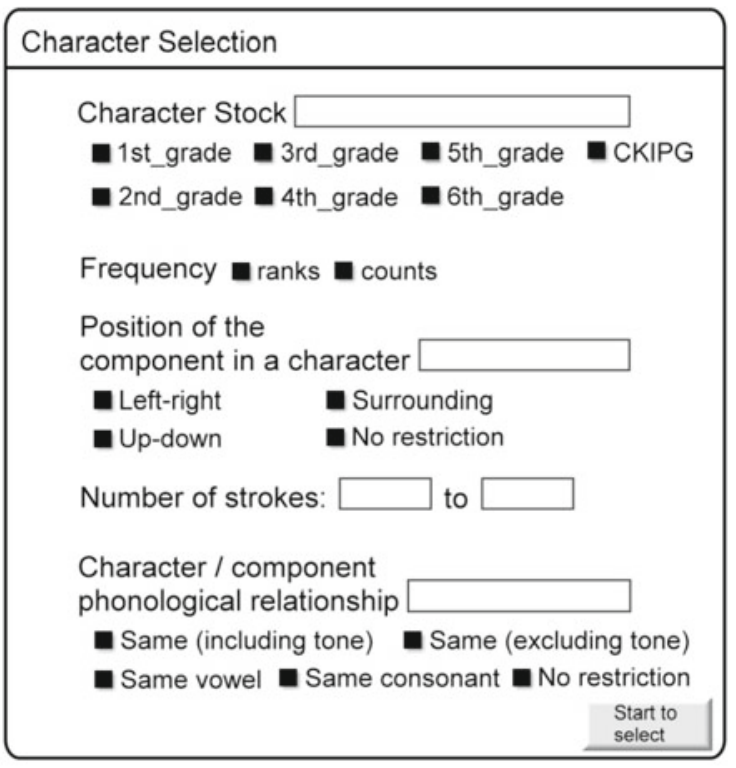

D

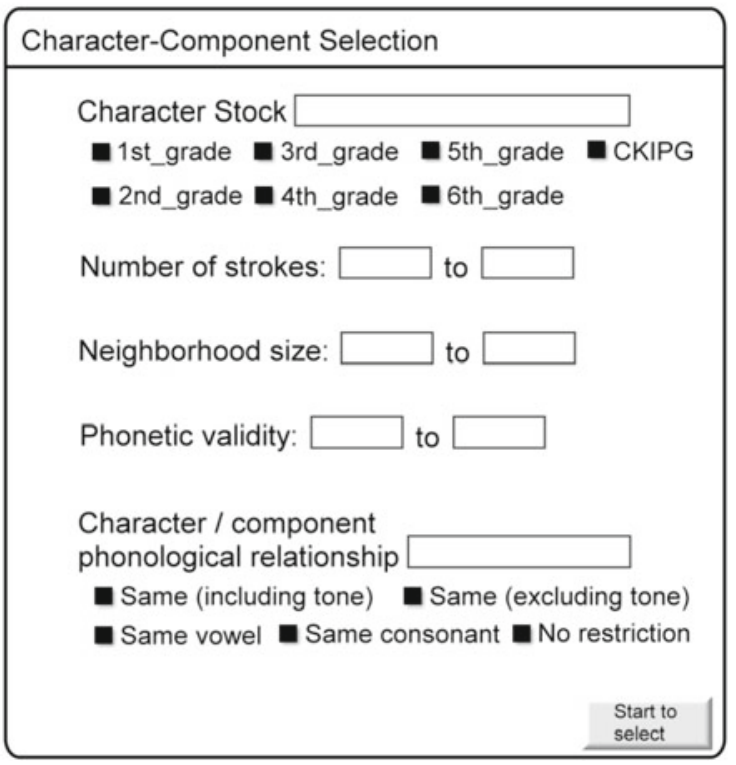

Figure 2. The parameter-setting windows corresponding to the four C-CAT functions.

listed in the database. Third, a set of internal codes not included in the Microsoft East Asian languages files represent the components used to construct Chinese characters (Chuang \& Hsieh, 2005). To install C-CAT, one needs to double-click on the setup file; installation proceeds and finishes automatically. A C-CAT desktop icon is created when the software is installed.

Double-clicking on the C-CAT icon starts the program and activates a function-selection window. Four buttons on the startup screen represent the four functions the software performs. After a user selects a function, the parametersetting window shown in Figure 2 is presented. In the window, C-CAT prompts the user to enter two types of information: the character stock from which the stimulus characters are to be selected and the linguistic properties of the selected character (or component) to be analyzed. The character stock defines the targeting set of the characters on which C-CAT operates. There are seven character stocks stored in C-CAT, and thus, a user has to specify which stock is to be used before analysis and selection can be performed.

\section{Character Stocks}

Characters are not only the building blocks of Chinese words, they are the main entries in the mental lexicon of a native Chinese speaker (Hoosain, 1992). However, not all 
Table 2

The Number of Characters Contained and the Number of Different Characters Used in the Seven Character Corpora Stored in C-CAT

\begin{tabular}{lcc}
\hline & $\begin{array}{c}\text { Total Number of } \\
\text { Characters Contained } \\
\text { in the Corpus }\end{array}$ & $\begin{array}{c}\text { Number of Different } \\
\text { Characters Used } \\
\text { in the Corpus } \\
\text { (Character Stock) }\end{array}$ \\
\hline CKIPG & $20,698,116$ & 5,656 \\
NICT 1st-6th grades & 80,651 & 2,687 \\
NICT 1st-5th grades & 60,331 & 2,306 \\
NICT 1st-4th grades & 40,448 & 1,814 \\
NICT 1st-3rd grades & 22,983 & 1,322 \\
NICT 1st-2nd grades & 10,617 & 896 \\
NICT 1st grade & 2,775 & 399 \\
\hline
\end{tabular}

Chinese characters are suitable for use as stimuli in a study investigating the cognitive processes involved in character recognition. The Kang-Xi Dictionary lists nearly 50,000 characters, and a common character dictionary lists about 15,000 . However, it is estimated that a Chinese college student knows only about 5,150 characters (Hue, 2003). This implies that, in a study investigating the content or operation of the mental lexicon, stimuli must be selected from a set of characters representing the sight vocabulary of the subjects. To address this concern, C-CAT contains one character stock suitable for studies using college students as subjects, and others for studies using elementary school students.

The corpus prepared by the Chinese Knowledge Information Processing Group (CKIPG, 1993) is a collection of 20 million Chinese characters sampled from the articles published in three major Taiwanese newspapers and in one magazine. According to the CKIPG, 5,656 characters were used to compose the articles collected (Table 2). In C-CAT, these characters were ranked according to their frequency of occurrence in the corpus. Judging from the number of characters in the character stock and the nature of the source from which the articles included in the corpus were sampled, the character stock extracted from the CKIPG is suitable for studies using college students, or people with equivalent education, as subjects.

The electronic files of articles containing the Chinese textbooks used in Taiwanese elementary schools were obtained from the publisher (NICT; National Institute for Compilation and Translation, 1995). Analysis of the characters used in the articles showed that there were $399,896,1,322$, $1,814,2,306$, and 2,687 characters used for the textbooks from Grades 1-6, respectively. For each grade, the characters of the NICT character stock were ranked according to their frequencies of occurrence in their respective corpora. For example, in the NICT 1st-grade corpus and character stock, the character "home" (Figure 10, /jia1/) occurs 25 times and ranks 24th. It occurs 398 times in the aggregate 1st- to 6th-grade corpus and ranks 30 th in the aggregate character stock. These six character stocks are suitable for studies using elementary school students as subjects.

\section{Character-Analysis Function}

After the user selects the character and its corpus, the character-analysis function counts the character's strokes and computes its linguistic frequency within the specified corpus. C-CAT can perform two kinds of computation related to the pronunciation of the character. It can analyze the components of the target character in terms of how they are arranged within the character, and, with respect to a component, the character's phonological regularity and neighborhood size. It can also fetch the characters from a character stock in accordance with the phonological constraint specified by the user.

To use the function, a user inputs a character and specifies a character stock containing that character to be analyzed (Figure 2A). To analyze the regularity of the character, the user specifies the phonological relationship between the character and a component (e.g., same vowel) that will be used to define regularity. To find a set of characters with pronunciations similar to that of the input character, the user must define what aspect of the pronunciation is similar (e.g., homophone excluding tone).

Character-component phonological relationship. In English, word regularity refers to the degree to which words follow the spelling-sound rules. In Chinese, Hue (1992) defined character regularity in a similar manner: A regular character has a pronunciation similar to the pronunciation of one of its components (i.e., the phonetic component), and an irregular character does not. C-CAT allows the user to define character regularity by specifying the phonological relationship between a character and its components - for example, a "regular" character could have the same pronunciation (with or without tone) as one of its components, or the pronunciation of the character could share a vowel (or a consonant) with one of its components.

Between-characters phonological relationship. C-CAT allows the user to specify the condition of retrieval for locating the characters in the character stock that share certain phonological features with the input character. The user can select from the four types of between-characters phonological relationships (homophones, homophones excluding tone, same vowel, and same consonant) or choose "no specification."

Table 3 shows an example of using this function to analyze the character "dried up" (Figure 1P, /ku1/). According to the linguistic properties specified by the user, the analyzed character is sampled from the NICT 1st- to 6th-grade character stock, and regular is defined as "the pronunciations of a character and one of its components share a vowel." It is required that the homophones (excluding tone) of the input character are to be retrieved from the character stock. Table 3 also presents the results of the analysis. In the output, C-CAT provides statistical information about the characters in the selected character stock and the results of the analysis. The results show that "dried up" occurs five times in the character corpus that the character stock was derived from and that the character frequency ranks 1,442 nd in the stock of 2,687 characters. The character comprises nine strokes and has two horizontally arranged components: "wood" (Figure 1Q, /mu4/) and "ancient" (Figure 1R, /ku3/). The pronunciations of both components share a vowel with the character "dried up." Finally, in the character stock, the component "wood" is included as a component in another 110 char- 
Table 3

An Example of Using C-CAT to Analyze a Chinese Character

\begin{tabular}{|c|c|}
\hline \multicolumn{2}{|r|}{ User’s Input } \\
\hline Character to be analyzed & See Figure $1 \mathrm{P}$ \\
\hline Character stock & NICT 1st-6th grades \\
\hline $\begin{array}{l}\text { Character-component } \\
\text { phonological relationship }\end{array}$ & Same vowel \\
\hline $\begin{array}{l}\text { Between-characters } \\
\text { phonological relationship }\end{array}$ & Same (excluding tone) \\
\hline \multicolumn{2}{|c|}{ C-CAT's Output } \\
\hline Corpus & NICT 1st-6th grades \\
\hline Corpus size & 80,651 \\
\hline $\begin{array}{l}\text { Number of different characters } \\
\text { used in the corpus }\end{array}$ & 2,687 \\
\hline Frequency & 5 \\
\hline Frequency rank & 1,442 \\
\hline Number of strokes & 9 \\
\hline Structure & horizontal \\
\hline Component & see Figure 1Q \\
\hline Regularity & yes \\
\hline Neighborhood size & 110 \\
\hline Component & see Figure 1R \\
\hline Regularity & yes \\
\hline Neighborhood size & 11 \\
\hline $\begin{array}{l}\text { Characters fit the phonological } \\
\text { condition specified }\end{array}$ & $\begin{array}{l}\text { "bitter" (Figure 1V1, /ku3/, 45, 356), } \\
\text { "cry" (Figure 1V2, /ku1/, 27, 508), } \\
\text { "warehouse" (Figure 1V3, /ku4/, 8, 1,150), } \\
\text { "brutal" (Figure 1V4, /ku4/, 1, 2,641), } \\
\text { "pants" (Figure 1V5, /ku4/, 1, 2,605) }\end{array}$ \\
\hline
\end{tabular}

${ }^{*}$ The two numbers represent the frequency and frequency rank of the character.

acters (i.e., the neighbors of "dried up"), and the component "ancient" is included in another 11 characters. Finally, C-CAT finds 5 characters matching the specified between-characters phonological relation. In the output, the characters are presented along with their frequencies and frequency ranks.

\section{Character Selection Function}

In research into Chinese character recognition, the choice of character stimuli is restricted by the purpose of the study. A researcher must check thousands of characters for the set of characters with the desired linguistic properties. A C-CAT user can search a character stock by specifying the following linguistic properties: charactercomponent phonological relationship, frequency ranking, arrangement of constituent components in a character, and number of strokes (see Figure 2B). These properties are described in the following sections.

Character-component phonological relationship. A user can configure C-CAT to select regular characters from a character stock. To use this feature, the user should define regularity in terms of the phonological relationship between a character and its constituent components. (See the Character-Analysis Function section.)

Frequency. In C-CAT, the characters of a character stock are ranked according to their frequencies of occurrence in the related character corpus. Thus, a user can use either "rank" or "frequency" to indicate the familiarity value of the characters to be selected.
Arrangement of components in a character. Most commonly used characters are compounds composed of a few components. The components of a compound character are often arranged side by side (horizontally). To a lesser extent, components are arranged vertically. A C-CAT user can specify the kind of compound characters to be selected from among the following choices: horizontal, vertical, nested (one component encompasses the other components), and no specification.

In the example presented in Table 4, the user wants characters composed of 8-12 strokes with constituent components arranged horizontally from the 1,000 most frequently used characters in the CKIPG character stock. In addition, the user defines regular to indicate that "the pronunciations of a character and one of its components are the same (excluding tone)." Thus, a selected character should have a component with the same pronunciation, regardless of tone, as that of the other character. In the 5,656 characters in the CKIPG character stock, 53 meet this criterion. In Table 4, the selected character "old" (Figure 1S, /gu4/) is used as an example. It comprises 9 strokes, and in the CKIPG corpus, its linguistic frequency and frequency rank are 3,980 and 732nd, respectively. The character has 19 neighbors in the CKIPG character stock, each of which has the character "ancient" (Figure 1R, /ku3/) as a component.

\section{Character-Component Analysis Function}

The information required for performing this function is shown in Figure 2C. When a user inputs a character 
Table 4

An Example of Using C-CAT to Select Characters

\begin{tabular}{|c|c|}
\hline \multicolumn{2}{|c|}{ User's Input } \\
\hline Character stock & CKIPG \\
\hline Frequency rank & $1-1,000$ \\
\hline Structure & Horizontal \\
\hline Number of strokes & $8-12$ \\
\hline $\begin{array}{l}\text { Character-component } \\
\text { phonological relationship }\end{array}$ & Same (excluding tone) \\
\hline \multicolumn{2}{|c|}{ C-CAT’s Output } \\
\hline Corpus & CKIPG \\
\hline Corpus size & $20,698,116$ \\
\hline $\begin{array}{l}\text { Number of different character } \\
\text { used in the corpus }\end{array}$ & 5,656 \\
\hline Character & see Figure $1 \mathrm{~S}^{*}$ \\
\hline Frequency & 3,980 \\
\hline Frequency rank & 732 \\
\hline Number of strokes & 9 \\
\hline Component & see Figure $1 \mathrm{R}$ \\
\hline Regularity & yes \\
\hline Neighborhood size & 19 \\
\hline
\end{tabular}

${ }^{*} \mathrm{C}$-CAT prints out all of the characters that meet the user-specified linguistic properties. The table presents only one of them as an example.

component, C-CAT computes the component's phonetic validity and searches through a character stock specified by the user for all the characters containing the component. The phonetic validity is the number of regular characters containing the component (Lo, Hue, \& Tsai, 2007), where regularity is defined by the "character-component phonological relationship" divided by the number of characters in the stock containing that component. A user can restrict the search to the specific position of the component in a character-for instance, the right half of a horizontal character.

As shown in Table 5, in the NICT 1st- to 6th-grade character stock, the component "ancient" (Figure 1R, /ku3/) is contained in 11 characters when one does not specify its position in a character. Using the user's definition of regularity (i.e., the pronunciations of a character and one of its components share a vowel), the phonetic validity of this component is .8. The frequency-weighted value of phonetic consistency can be computed from the output (Jared, McRae, \& Seidenberg, 1990). For the component "ancient," the value is .8 .

\section{Character-Component Selection Function}

C-CAT is able to search through a character stock for those characters that can be used to construct other characters. C-CAT can base the search on the restriction of the character stock and on the three user-specifiable linguistic properties: number of strokes, neighborhood size, and phonetic validity (Figure 2D). In the example presented in Table 6, the user asked C-CAT to search the CKIPG character stock for all 5- to 10 -stroke character components that appear in 5-15 different characters. The user specified that the pronunciation of a regular character shares a consonant with one of its components. With this definition of regularity, the phonetic validity values of each of the selected "components" (or rather, characters) are computed. As a result, C-CAT found 194 character components meeting the criteria. For example, the component "bureau" (Figure 1T, /si1/) is a simple, but independent, Chinese character that is composed of 5 strokes and is a component of 5 composite characters. In 3 of the 5 characters, their pronunciations share the same consonant/s/ with "bureau," and thus, the phonetic validity of "bureau" is .6.

\section{System Requirements and Saving C-CAT Output}

C-CAT can be installed on a personal computer (PC) with or without a Traditional Chinese version of Windows XP. To be installed on a PC not running Traditional Chinese Windows XP, the C-CAT software requires the following system configuration: a Windows XP operating system, the Microsoft East Asian languages files, and the Microsoft Global IME (input method editor). Although East Asian languages and Global IME files are included in the Windows XP package, they are not routinely installed. The procedure for installing them can be found on the Microsoft Web site. The default text editor for the output of C-CAT is the Windows Notepad. It is suggested that a user save an output in a comma-separated format (i.e., the CSV file type), which MS Excel can read and use to present the output in a spreadsheet.

\section{Limitations}

C-CAT follows a set of design principles that guide how a character can be decomposed into its components. Without such constraints, it would be difficult to design an executable and efficient algorithm for character analysis. However, these principles also create limitations for C-CAT. First, research results indicate that the radical of a phonetic component affects the lexical decision of the

Table 5

An Example of Using C-CAT to Analyze a Character Component

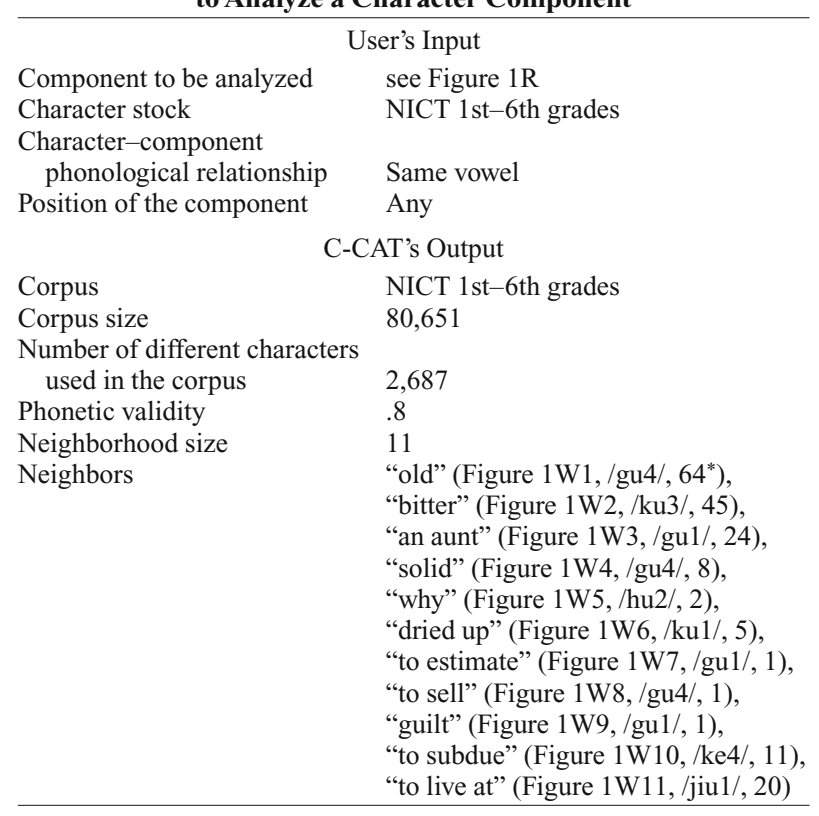

${ }^{*}$ Character frequency. 
Table 6

An Example of Using C-CAT to Select Character Components

\begin{tabular}{ll}
\hline & User's Input \\
Character stock & CKIPG \\
$\begin{array}{l}\text { Number of strokes } \\
\text { Character-component } \\
\text { phonological relationship }\end{array}$ & $5-10$ \\
Phonetic validity & Same consonant \\
Neighborhood size & $0.0-1.0$ \\
& $5-15$ \\
& C-CAT's Output \\
Corpus & CKIPG \\
Corpus size & $20,698,116$ \\
Number of different characters & \\
used in the corpus & 5,656 \\
Component & see Figure 1T* \\
Number of strokes & 5 \\
Phonetic validity & .6 \\
Neighborhood size & 5 \\
Neighbors & "words" (Figure 1X1,/ci2/, 1,701†), \\
& "to feed" (Figure 1X2,/si4/, 525), \\
& "to serve" (Figure 1X3,/si4/, 181), \\
& "an ancestral shrine" (Figure 1X4,/ci2/, 81), \\
& "a descendant" (Figure 1X5,/si4/, 76) \\
\hline
\end{tabular}

${ }^{*} \mathrm{C}$-CAT prints out all the components that meet the user-specified linguistic properties. The table presents only one of them as an example. †Character frequency.

character containing the phonetic component (Taft \& Zhu, 1997). To design an experiment studying the issue further, one would have to account for the characteristics of the subcomponents of a stimulus character's constituent components. However, C-CAT can only analyze a character into two components and can compute the characteristics of the two components and the composite character.

Second, in C-CAT, variant forms of a character are treated as different characters. However, C-CAT treats a character and radical that share a form as the same character and assigns them to a single entry. This may create miscalculation for certain characteristics of a character containing a component that has a variant written form. For example, the components in Figures $1 \mathrm{U}$ and $1 \mathrm{E}$ are variant written forms of the same radical, "heart" (/xin1/). In the NICT 1st- and 2nd-grade character stocks, 10 characters contain the component in Figure $1 \mathrm{U}$, and 11 characters contain the component in Figure 1E. Because the component in Figure 1E is also a character, a miscalculation results when the neighborhood size of a character using it as the phonetic component is calculated. Similarly, it is not known from the C-CAT output how many characters use "heart" as a radical.

Third, in C-CAT, a character with multiple pronunciations has multiple entries. Thus, a character with two pronunciations is processed twice while it is the target of analysis. In such circumstances, C-CAT often outputs redundant information, which increases reading difficulty.

Addressing the limitations mentioned above is under consideration as part of a planned revised edition of C-CAT. However, we admit that the task is difficult, because new algorithms will be required so that a character can be analyzed into a set of "meaningful" components and so that C-CAT can recognize a character's variant forms and a component's role in a character (e.g., a radical).

\section{AUTHOR NOTE}

We thank the two anonymous reviewers of this article for their useful comments. This research was supported by Grant NSC93-2413-H002-019 to C.-W.H. from the National Science Council of the Republic of China. The software and the user's manual of C-CAT can be retrieved from http://140.112.62.230/C-CAT/. Correspondence concerning this article should be addressed to C.-W. Hue, Department of Psychology, National Taiwan University, No. 1, Sec. 4, Roosevelt Road, Taipei, 10617, Taiwan (e-mail: hue@ntu.edu.tw).

\section{REFERENCES}

BARber, H. A., \& KutAS, M. (2007). Interplay between computational models and cognitive electrophysiology in visual word recognition. Brain Research Reviews, 53, 98-123.

Chen, Y. P., Allport, D. A., \& Marshall, J. C. (1996). What are the functional orthographic units in Chinese word recognition: The stroke or the stroke pattern? Quarterly Journal of Experimental Psychology, 49A, 1024-1043.

Chinese Knowledge Information Processing Group (1993). Corpus-based frequency count of characters in journal Chinese: Corpus-based research (No. 1). Taipei, Taiwan: Academia Sinica Institute of Information Science.

Chuang, D. M., \& Hsien, C. C. (2005). Design and application of a Chinese character database. In Proceedings of the International Conference on Chinese Characters and Globalization (pp. 119-133). Taipei, Taiwan: Taipei City Government.

DeFrancis, J. (1984). The Chinese language: Fact and fantasy. Honolulu: University of Hawaii Press.

Ding, G., Peng, D., \& Taft, M. (2004). The nature of the mental representation of radicals in Chinese: A priming study. Journal of Experimental Psychology: Learning, Memory, \& Cognition, 30, 530-539.

Fang, S. P., Horng, R. Y., \& Tzeng, O. J. L. (1986). Consistency effects in the Chinese character and pseudo-character naming tasks. In H. S. R. Gao \& R. Hoosain (Eds.), Linguistics, psychology, and the Chinese language (pp. 11-21). Hong Kong: University of Hong Kong, Centre of Asian Studies.

Feldman, L. B., \& SioK, W. W. T. (1997). The role of component function in visual recognition of Chinese characters. Journal of Experimental Psychology: Learning, Memory, \& Cognition, 23, 776-781.

Feldman, L. B., \& SioK, W. W. T. (1999). Semantic radicals contribute 
to the visual identification of Chinese characters. Journal of Memory \& Language, 40, 559-576.

Frost, R., Katz, L., \& Bentin, S. (1987). Strategies for visual word recognition and orthographical depth: A multilingual comparison. Journal of Experimental Psychology: Human Perception \& Performance, 13, 104-115.

GLushko, R. J. (1979). The organization and activation of orthographic knowledge in reading aloud. Journal of Experimental Psychology: Human Perception \& Performance, 5, 674-691.

Hoosain, R. (1992). Psychological reality of the word in Chinese. In H.-C. Chen \& O. J. L. Tzeng (Eds.), Language processing in Chinese (pp. 111-130). Amsterdam: North-Holland.

Hsiao, J. H.-W., Shillcock, R., \& LAVIdor, M. (2006). A TMS examination of semantic radical combinability effects in Chinese character recognition. Brain Research, 1078, 159-167.

Hsiao, J. H.-W., Shillcock, R., \& LeE, C.-Y. (2007). Neural correlates of foveal splitting in reading: Evidence from an ERP study of Chinese character recognition. Neuropsychologia, 45, 1280-1292.

Hsieh, C. C., Chuang, D. M., Chang, T. L., \& Hsu, W. J. (1995). Design and application of a Chinese character database. In Proceedings of the Sixth National Conference on the Study of Written Chinese Characters (pp. 9-22). Taipei, Taiwan: National Chung Hsing University.

HuE, C.-W. (1992). Recognition processes in character naming. In H.-C. Chen \& O. J. L. Tzeng (Eds.), Language processing in Chinese (pp. 93-107). Amsterdam: North-Holland.

HuE, C.-W. (2003). Number of characters a college student knows. Journal of Chinese Linguistics, 31, 300-339.

Jared, D., McRae, K., \& SeidenberG, M. S. (1990). The basis of consistency effects in word naming. Journal of Memory \& Language, 29, 687-715.

Kuo, W.-J., YeH, T.-C., LeE, C.-Y., Wu, Y. T., Chou, C.-C., Ho, L.-T., ET AL. (2003). Frequency effects of Chinese character processing in the brain: An event-related fMRI study. NeuroImage, 18, 720-730.

LeCK, K. J., WeEKES, B. S., \& CHEN, M. J. (1995). Visual and phonological pathways to the lexicon: Evidence from Chinese readers. Memory \& Cognition, 23, 468-476.

LeE, C.-Y., Tsai, J.-L., Kuo, W.-J., Yeh, T.-C., Wu, Y.-T., Ho, L.-T., ET AL. (2004). Neuronal correlates of consistency and frequency effects on Chinese character naming: An event-related MRI study. NeuroImage, 23, 1235-1245.

Lee, C.-Y., Tsai, J.-L., Su, E. C.-I., Tzeng, O. J. L., \& Hung, D. L. (2005). Consistency, regularity, and frequency effects in naming Chinese characters. Language \& Linguistics, 6, 75-107.
Liu, C.-L., Hue, C.-W., Chen, C.-C., Chuang, K.-H., Liang, K.-C., WANG, Y.-H., ET AL. (2006). Dissociated roles of the middle frontal gyri in the processing of Chinese characters. NeuroReport, 17, 1397-1401.

Lo, M., Hue, C.-W., \& TsaI, F.-Z. (2007). Chinese readers' knowledge of how Chinese orthography represents phonology. Chinese Journal of Psychology, 49, 315-334.

National Institute FOR Compilation AND Translation (1995). Elementary school Chinese textbooks. Taipei, Taiwan: National Institute for Compilation and Translation.

Perfetti, C. A., \& TAN, L. H. (1998). The time course of graphic, phonological, and semantic activation in Chinese character identification. Journal of Experimental Psychology: Learning, Memory, \& Cognition, 24, 101-118.

SeidenberG, M. S. (1985). The time course of phonological code activation in two writing systems. Cognition, 19, 1-30.

Shu, H., Anderson, R. C., \& Wu, N. (2000). Phonetic awareness: Knowledge of orthography-phonology relationships in the character acquisition of Chinese children. Journal of Educational Psychology, 92, 56-62.

TAFT, M., \& ZHU, X. (1997). Submorphemic processing in reading Chinese. Journal of Experimental Psychology: Learning, Memory, \& Cognition, 23, 761-775.

Tan, L. H., Feng, C.-M., Fox, P. T., \& GaO, J.-H. (2001). An fMRI study with written Chinese. NeuroReport, 12, 82-88.

WANG, M.-Y. (2002). The nature of character-component interaction in Chinese character perception. Psychologia, 45, 162-175.

WANG, M.-Y. (2006). Examining the bias for orthographic components using an apparent motion detection task. Psychologia, 49, 193-213.

WeEkES, B. S., CHEN, M. J., \& LiN, Y.-B. (1998). Differential effects of phonological priming on Chinese character recognition. Reading \& Writing, 10, 201-222.

WeEkes, B. [S.], \& ZHANG, B. Y. (1999). Chinese character recognition in the left and right visual fields. Brain \& Cognition, 40, 269-272.

\section{NOTE}

1. Traditional Chinese characters are used in Taiwan, Hong Kong, and Macao. In mainland China and Singapore, simplified characters are used.

(Manuscript received August 10, 2007; revision accepted for publication April 16, 2008.) 